\title{
Article
}

\section{Does text contrast mediate binocular advantages in reading?}

Jainta, Stephanie, Nikolova, Mirela and Liversedge, Simon Paul

Available at https://clok.uclan.ac.uk/22340/

Jainta, Stephanie, Nikolova, Mirela and Liversedge, Simon Paul orcid iconORCID: 0000-0002-8579-8546 (2017) Does text contrast mediate binocular advantages in reading? Journal of Experimental Psychology: Human Perception and Performance, 43 (1). pp. 55-68. ISSN 0096-1523

It is advisable to refer to the publisher's version if you intend to cite from the work. http://dx.doi.org/10.1037/xhp0000293

For more information about UCLan's research in this area go to http://www.uclan.ac.uk/researchgroups/ and search for <name of research Group>.

For information about Research generally at UCLan please go to http://www.uclan.ac.uk/research/

All outputs in CLoK are protected by Intellectual Property Rights law, including Copyright law. Copyright, IPR and Moral Rights for the works on this site are retained by the individual authors and/or other copyright owners. Terms and conditions for use of this material are defined in the policies page.

\section{CLoK}

Central Lancashire online Knowledge www.clok.uclan.ac.uk

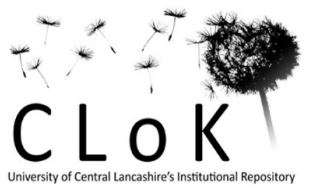




\section{Does text contrast mediate binocular advantages in reading?}

Stephanie Jainta ${ }^{1}$, Mirela Nikolova ${ }^{2} \&$ Simon P. Liversedge ${ }^{3}$

Affiliations:

${ }^{1}$ : IfADo - Leibniz Research Centre for Working Environment and Human Factors Ardeystrasse 67, D-44139 Dortmund, Germany. Tel: 0049-1084-272, Fax: 00491084401, Email: jainta@ifado.de

2 .

2: School of Psychology, University of Southampton, Highfiled Campus, Southampton SO17 1BJ, UK. Tel: 0044-23-8059-9399, Fax: 0044-23-8059-2606,

Email: M.Nikolova@soton.ac.uk

3.

': School of Psychology, University of Southampton, Highfiled Campus, Southampton SO17 1BJ, UK. Tel: 0044-23-8059-2917, Fax: 0044-23-8059-2606,

Email: S.P.Liversedge@soton.ac.uk 


\begin{abstract}
Humans typically make use of both of their eyes in reading and efficient processes of binocular vision provide a stable, single percept of the text. Binocular reading also comes with an advantage: reading speed is high and word frequency effects (i.e., faster lexical processing of words that are more often encountered in a language) emerge during fixations, which is not the case for monocular reading (Jainta, Blythe, \& Liversedge, 2014). A potential contributor to this benefit is the reduced contrast in monocular reading: reduced text contrasts in binocular reading are known to slow down reading and word identification (Reingold \& Rayner, 2006). To investigate whether contrast reduction mediates the binocular advantage, we tested adults in 3 experiments. We first replicated increased reading time and nullified frequency effects for monocular reading (Experiment 1). Next, we reduced the contrast for binocular but whole sentences to $70 \%$ (Weber-contrast); this reading condition resembled monocular reading, but found no effect on reading speed and word identification (Experiment 2). A reasonable conclusion, therefore, was that a reduction in contrast and thus, a critical aspect of low level visual processing, is not the (primary) factor that mediates less efficient lexical processing under monocular viewing conditions. In a third experiment (Experiment 3) we reduced the text contrast (of the whole sentence) to $40 \%$ and the pattern of results showed that, globally, reading was slowed down but clear word frequency effects were present in the data. Thus, word identification processes during reading (i.e., the word frequency effect) were qualitatively different in monocular reading compared to effects observed when text was read with substantially reduced contrast.
\end{abstract}


When reading text on a screen or in a book, humans typically make use of both of their eyes and efficient processes of binocular coordination and vision typically provide a stable, single percept of the text (Heller \& Radach, 1998; Jainta et al., 2014; Jainta, Hoormann, Kloke, \& Jaschinski, 2010; Jainta \& Jaschinski, 2012; Kirkby, Webster, Blythe, \& Liversedge, 2008; Liversedge, Rayner, White, Findlay, \& McSorley, 2006; Liversedge, White, Findlay, \& Rayner, 2006). Generally, the eyes perform yoked, rapid eye-movements during reading, that is, saccades, which bring new words (or parts of words) into foveal regions of the retina. Between saccades the eyes fixate for about $200-300 \mathrm{~ms}$, on average, and the variability in these fixation times is thought to reflect cognitive processing of the information being read (Kliegl, Nuthmann, \& Engbert, 2006; Rayner, 1998).

According to currently implemented computational models of eye movement control during reading, such as E-Z Reader ((Pollatsek, Reichle, \& Rayner, 2006; Rayner, Ashby, Pollatsek, \& Reichle, 2004; Reichle et al., 2013; Reichle, Rayner, \& Pollatsek, 2003) and SWIFT (Engbert, Longtin, \& Kliegl, 2002; Engbert, Nuthmann, Richter, \& Kliegl, 2005; Richter, Engbert, \& Kliegl, 2006), the time spent fixating a word is jointly determined by the extent to which it is efficiently parafoveally pre-processed prior to fixation, and the ease with which it is lexically identified, usually, though not always, upon fixation. Properties of a word, such as its lexical frequency, for example, modulate fixation times: words which occur less frequently in a language produce longer fixation durations (Inhoff \& Rayner, 1986; Rayner \& Duffy, 1986). This word-frequency effect demonstrates nicely that linguistic processing, and word identification in particular, determine when we move our eyes as we read (Rayner, 1998; Rayner, Liversedge, White, \& Vergilino-Perez, 2003).

Current understanding also suggests that visual input quality impacts on early word recognition processes in reading (Pollatsek et al., 2006; Rayner et al., 2004; Reichle et al., 2013; Reichle et al., 2003; Reingold \& Rayner, 2006): for example, presenting blurred text (Jainta, Dehnert, Heinrich, \& Jaschinski, 2011), filtering of spatial frequencies (Jordan, McGowan, \& Paterson, 2012; Kwon \& Legge, 2012; Legge, Pelli, Rubin, \& Schleske, 1985; Paterson, McGowan, \& Jordan, 2013) or reductions of text contrast have been shown to 
considerably increase fixation durations (Drieghe, 2008; Glaholt, Rayner \& Reingold, 2014; Johansson, Pansell, Ygge, \& Seinmyr, 2014; Legge, Parish, Luebker, \& Wurm, 1990; Legge, Rubin, \& Luebker, 1987; Liu, Li \& Han, 2015; Paterson, McGowan \& Jordan, 2012; Reingold \& Rayner, 2006; Sheridan \& Reingold, 2013; Wang \& Inhoff, 2010; White \& Staub, 2012). Moreover, Sheridan and Reingold (2013) reported an interactive effect of reduced text contrast and word frequency, exhibited in increased processing times for low-frequency words when a single target word was presented with low contrast $(40 \%$ Weber-contrast, calculated from reported luminance) within a normally presented sentence frame. Interestingly, a different pattern of results was obtained by Liu, Li and Han (2015), who found an overall additive effect of reduced stimulus quality when a target word in Chinese sentences was reduced in contrast (down to 15\%; Weber-contrast, calculated from reported luminance). Despite the difference in these findings, the cited studies suggest that reducing stimulus quality impacts on global reading performance, as well as on linguistic processing. One limitation of this literature is that the influence of stimulus contrast on both global eye movement behaviour and target word identification was not investigated in the same experiment. Further, typical binocular reading comes with binocular advantages (Heller \& Radach, 1998; Jainta et al., 2014; Jainta \& Jaschinski, 2012; Sheedy, Bailey, Buri, \& Bass, 1986). When sentences are read monocularly, sentence or paragraph reading times increase and frequency effects are mitigated (i.e., there is no observable benefit for high compared to low frequency words), reflecting a disruption to the efficiency of lexical processing. Along with inefficient word identification during monocular reading, we also recently showed that under binocular reading conditions, lexical identification was enabled to such an extent that frequency effects emerged during the very first fixation on a binocularly fixated word even when parafoveal preview of that word was monocular (Jainta et al., 2014). However, these word frequency effects were smaller compared to those that occurred for binocular reading. Therefore, we concluded that when the quality of the visual representation of the text was reduced due to (parafoveal or foveal) monocular viewing conditions, lexical processing became less efficient, and specifically, the identification of high frequency words was inhibited. However, to date no specific aspect of visual processing has 
been suggested as to the cause of such a specific binocular advantage for lexical processing. A primary aim of the present study was to explore a possible factor that might contribute to both, global and specific binocular advantages in reading.

The literature on binocular vision (Blake \& Wilson, 2011; Changizi, 2009; Howard, 2012; Leigh \& Zee, 2006; Schor \& Ciuffreda, 1983; Steinman, Steinman, \& Garzia, 2000) suggests that binocular advantages might be purely induced by differences at threshold levels of discrimination. Under such conditions of reduced visual quality primary visual features (e.g. luminance) and their direct derivatives (e.g. local contrast) are extracted and channelled more efficiently when viewing is binocular rather than monocular. Binocular advantages in this context are traditionally thought to relate closely to binocular summation. The combined signal from the two visual receptors provides a richer source of information in relation to detection of, or discriminating between, visual features than the signal available from each individual receptor alone (Blake, Sloane, \& Fox, 1981). At low levels of overall luminance, it is argued that summation of the inputs from both eyes produces a clear advantage: classical ideas of a simple linear summation of two neural signals (with equal but uncorrelated noise) showed binocular summation effects such that monocular luminance thresholds and monocular contrast thresholds were considerably higher compared to binocular thresholds. In fact, monocular thresholds are about 1.4 times the binocular threshold $(\sqrt{2})$ which corresponds to a change of about $40 \%$ visual acuity (Blake \& Wilson, 2011; Howard, 2012). Thus, at threshold level when visual stimuli need to be detected or discriminated between, summation of the visual inputs yields a direct and considerable advantage. In contrast, when luminance conditions are far above threshold - as they typically are in normal reading - such a simple and straightforward summation of neural signals is implausible, since this would theoretically lead to large, noticeable changes in the perception of brightness and contrast, when viewing conditions switched from monocular to binocular, or when targets appear in different positions within the binocular or monocular field of view (Blake \& Wilson, 2011; Howard, 2012). Subjective reports from previous reading experiments have also indicated that in experimental situations where luminance is above threshold, there is a dissociation between perception and 
performance, such that binocular advantages still occur, even though participants cannot reliably discriminate between a binocular and a monocular stimulus (Jainta et al., 2014). Furthermore, recent models of binocular summation account for such differences in respect to near or above threshold stimuli and exhibit a complex, multi-channel architecture incorporating dynamic aspects of vision and ocular dominance (see Howard (2012), or Blake and Wilson (2011) for an overview). Such models account for several well-known observations, including the fact that binocular advantages in visual acuity increase when the contrast of the stimulus is reduced (i.e. participants benefit increasingly from binocular vision when viewing conditions approach threshold). Very recently, Johansson et al., (2014) varied the contrast of monocular and binocular text presentations and showed that when contrasts are lowered, reading speed decreases and fixation durations increase. More importantly, binocular advantages in reading increased with reduced contrast of the presented text: the lower the contrast (down to $10 \%$ ), the longer (up to $20 \%$ ) the fixation durations in monocular reading compared to binocular reading. Thus, besides an overall slowing of binocular reading when text contrast was reduced (Drieghe, 2008; Glaholt, Rayner \& Reingold, 2014; Johansson, Pansell, Ygge, \& Seinmyr, 2014; Legge, Parish, Luebker, \& Wurm, 1990; Legge, Rubin, \& Luebker, 1987; Liu, Li \& Han, 2015; Paterson, McGowan \& Jordan, 2012; Reingold \& Rayner, 2006; Sheridan \& Reingold, 2013; Wang \& Inhoff, 2010; White \& Staub, 2012 ), variation of text contrast also impacts on the extent to which participants benefit from binocular vision when processing written text (Johansson et al., 2014).

We therefore set out to explore whether the binocular advantages for lexical processing we observe in binocular compared to monocular reading might arise due to simple changes in contrast under the different viewing conditions. It is important to note that manipulations of contrast have previously been used to investigate interactions between visual features of the single words in text and lexical processing during sentence reading, (e.g. in Sheridan \& Reingold, 2013, or by Liu, Li \& Han, 2015). Nevertheless, in those studies contrast manipulations have always been limited to a single target word within the sentence and the levels of contrast were not specifically chosen to correspond to those observed in a monocular 
viewing situation. Critically, for our study, we manipulated the contrast for the entire sentence (i.e., all the words in a sentence rather than a single target word) in order to mimic changes which come naturally during all fixations in monocular sentence reading. In total we collected data in 3 experiments: in Experiment 1 we aimed to replicate our previous findings of a binocular advantage for word identification in reading (Jainta et al., 2014). Therefore we presented text monocularly and binocularly and expected (a) a general slowing for monocular reading, and (b) that the processing of a high frequency word (that is comparatively easy to identify), should be slowed down when sentences were read monocularly relative to when they were read binocularly. In other words, word frequency effects should be reduced under monocular reading. Next, in Experiment 2, we presented binocular text with full contrast (99\%, calculated as Weber-contrast) and text presented with only partial contrast such that in terms of its contrast characteristics, it resembled text presented under monocular conditions. In this situation, the text was presented with approximately $70 \%$ of contrast. To re-iterate, the full contrast $(99 \%)$ resembled 1.4 times of the lower contrast $(70 \%)$ - and this reflects the (theoretical maximal) difference in contrast thresholds between monocular and binocular viewing (Blake \& Wilson, 2011; Howard, 2012). Consequently, if text contrast impacts on reading performance (Drieghe, 2008; Glaholt, Rayner \& Reingold, 2014; Johansson, Pansell, Ygge, \& Seinmyr, 2014; Legge, Parish, Luebker, \& Wurm, 1990; Legge, Rubin, \& Luebker, 1987; Liu, Li \& Han, 2015; Paterson, McGowan \& Jordan, 2012; Reingold \& Rayner, 2006; Sheridan \& Reingold, 2013; Wang \& Inhoff, 2010; White \& Staub, 2012) and binocular advantages are due to altered contrast conditions in monocular reading as hypothesized above, we predicted that a lower text contrast of $70 \%$ should clearly affect reading performance in a manner comparable to monocular text presentations in Experiment 1: reading times should increase and the processing of a high frequency word should be inhibited when words were read with low contrast. Alternatively, if contrast manipulations additively affect word frequency effects (Liu, Li \& Han, 2015), or even increase word frequency effects, by slowing processing of low frequency words (Sheridan \& Reingold, 2013), a different pattern should emerge whereby changes should occur for low and high frequency words together. 
In our final experiment, Experiment 3, we reduced the text contrast to approximately $40 \%$, that is, to less than half of the full contrast in order to provide a very strong manipulation of contrast similar to manipulations in previous studies (Drieghe, 2008; Glaholt, Rayner \& Reingold, 2014; Johansson, Pansell, Ygge, \& Seinmyr, 2014; Legge, Parish, Luebker, \& Wurm, 1990; Legge, Rubin, \& Luebker, 1987; Liu, Li \& Han, 2015; Paterson, McGowan \& Jordan, 2012; Pollatsek et al., 2006; Rayner et al., 2004; Reichle et al., 2013; Reichle et al., 2003; Reingold \& Rayner, 2006; Sheridan \& Reingold, 2013; Wang \& Inhoff, 2010; White \& Staub, 2012). More specifically, we used contrast reductions previously reported in Sheridan and Reingold (2013) and anticipated that such a strong manipulation would almost certainly result in a general slowing of reading. We also expected to observe a significant word frequency effect, as in Sheridan and Reingold (2013), which might be modified by the contrast reduction in either an additive or an interactive fashion. Such a pattern of results would be clearly qualitatively different from effects that arise from monocular reading.

\section{General Methods}

\section{Orthoptic Examination}

All 64 participants showed good stereovision (60 s of arc or better, tested with the TNO random dot test) and refractive errors ranged from -0.25 to 0.125 (D). None of our participants wore glasses or contact lenses during reading. We also tested visual acuity for each eye at a standard far distance $(6 \mathrm{~m})$ and the testing distance of $60 \mathrm{~cm}$. Only participants showing good visual acuity in each eye (better than 0.8 in decimal units) for the text presentation distance of $60 \mathrm{~cm}$ were included into our participant pool. Further, the visual acuity difference between the eyes of each participant did not exceed 0.2 decimal units. We also evaluated vergence and accommodation ranges and found no obvious deviation from typical ranges (Evans, 2002). As part of our initial orthoptic examination session, all participants were also tested for eye dominance using a sighting test: the participant had to fixate a black cross target (displayed at $5 \mathrm{~m}$ distance) through a hole $(3 \mathrm{~cm}$ in diameter $)$ in the middle of a simple card $(20 \mathrm{~cm}$ wide and $13 \mathrm{~cm}$ high; see Jainta \& Jaschinski, 2012 for more details). Only 24 of our participants 
showed a left eye dominance and we therefore replicated a previously reported observation that most people in random samples show a right eye dominance, when tested with sighting tests (Mapp, Ono \& Barbeito, 2003; Ehrenstein, Arnold-Schulz-Gahmen, \& Jaschinski, 2005).

\section{Stimuli}

Participants read 40 German sentences. In $50 \%$ of all presentations the sentence was followed by a comprehension question to ensure that participants concentrated on understanding the sentences. We selected sentences containing 8 to 13 words, and the sentences differed in total length from 55 to 75 character spaces. Sentences were presented in black, Courier New font size 12, on a white background with a luminance of $48 \mathrm{~cd} / \mathrm{m}^{2}$ at a screen refresh rate of $100 \mathrm{~Hz}$. The average letter width was 0.33 deg (20 min arc). The surrounding room lighting was approximately 40 lux. Viewing distance was set to $60 \mathrm{~cm}$. We also included a target word in each sentence that could be of high (86 to 596 per million) or low (1 to 20 per million) word frequency (Celex2 German, Version 2.0; Baayen, Piepenbrock, \& Gulikers, 1995). This target word always contained 8 letters and was presented centrally on the screen, that is, its first letter was just to the right of the centre of the screen at eye height. Each target word was also preceded and followed by a 5 to 6 letter word. In each experiment, all participants read 20 sentences containing high frequency words and 20 sentences containing low frequency words, while the combination sentence frame (see Figure 1) and word frequency was counterbalanced between participants. Target word predictability in these sentence frames was also assessed by providing an additional group of 17 participants with the beginning of each sentence frame and asking them to write a word that could fit as the next word in the sentence. The average predictability was low, amounting to $1.8 \%$ for the highfrequency target words and $0.1 \%$ for the low-frequency target words. Predictability difference between high-frequency and low-frequency words was not statistically significant $(t<1)$. Insert Figure 1 around here

To minimize selection effects we randomly assigned our participants to one of the 3 experiments reported in this study. Although participants in the 3 experiments were different, 
the participant groups were homogenous in terms of age and educational background. Our rigorous orthoptic examination also indicated that all participants had normal vision, with very similar monocular and binocular visual acuity and no large deviations from typical vergence and accommodation ranges.

\section{Eye movement measurement and general procedure}

We recorded eye movements with the video-based EyeLink II, which tracks both eyes simultaneously with a theoretical noise-limited resolution of 0.01 ( $0.6 \mathrm{~min}$ arc) and a velocity noise of $<3 \mathrm{deg} / \mathrm{s}$ for two-dimensional eye tracking (details provided by SR Research Ltd., Osgoode, ON, Canada). The EyeLink II was not head-mounted, but the cameras were fixed to the chin- and forehead-rest that was used to stabilize the head (see Jainta and Jaschinski (2012) for a picture of the set-up). A narrow temporal rest further minimized head movements.

For the eye tracker calibrations, participants were requested to carefully fixate on targets that randomly appeared for $1000 \mathrm{~ms}$ at one of 3 horizontal positions on the screen (5 deg to the left, centre and 5 deg to the right). To draw attention to the calibration targets, the diameter of the spot initially subtended $1 \mathrm{deg}$ and shrank immediately to a remaining cross of $8.1 \times 8.1 \mathrm{~min}$ arc (stroke width: $2.7 \mathrm{~min}$ arc). The remaining cross was visible for $400 \mathrm{~ms}$ during which calibration data were stored. After calibration runs, a fixation cross appeared at the left calibration position. After $1000 \mathrm{~ms}$, a sentence was shown and the participants clicked on a mouse button to indicate when they had finished reading. The sentence then disappeared, and a second fixation cross was presented at the right calibration position. After $1000 \mathrm{~ms}$, this second cross was replaced in half of the trials by a multiple choice question pertaining to the content of the sentence. In the remaining half of the trials, a central fixation cross appeared, which participants fixated for an additional $1000 \mathrm{~ms}$. Thereafter, the left fixation cross appeared again, and a new sentences trial started. Full calibration runs were repeated after every 5 sentences.

\section{Data selection and parameter extraction}


Only horizontal eye movements were analyzed. From the separate signals of the two eyes, we calculated the conjugate eye movement ((left eye + right eye)/2; i.e., the version signal). The onset and offset of the horizontal saccades was defined as the time when the eye velocity of the conjugate signal exceeded or dropped below, respectively, $10 \%$ of the maximum velocity. Fixations shorter than 80 ms or longer than 1200 ms (Liversedge, White, et al., 2006) were excluded. Sentence reading time, number of fixations and regressions and saccade amplitude were calculated. For target word fixations, first fixation durations, gaze durations and total reading times were also calculated.

\section{Statistical analysis}

For data analysis, we used a linear mixed-effects model (Imer from package Ime4 (Pinheiro \& Bates, 2000; Venables \& Smith, 2001) in R (2008). The p-values were estimated by using posterior distributions for the model parameters obtained by Markov Chain Monte Carlo sampling, which include a typical sample size of 10000 (Baayen, Davidson, \& Bates, 2008). Predictors were centered, variables were transformed, if necessary, and the model was applied to the non-aggregated data extracted for each fixation. While reading conditions (binocular vs. monocular; high vs. low contrast) were defined as a fixed effect, participants and sentences were treated as random effects, with the maximal random structure justified by design (Barr, Levy, Scheepers, \& Tily, 2013). For all analyses the estimated fixed effect (b) with its standard error (SE) and the p-value are reported.

\section{Experiment 1}

The purpose of this experiment was to replicate previous findings showing a binocular advantage in reading, specifically in relation to word identification (Jainta et al., 2014).

\section{Methods}

Participants. 23 adults (12 females and 11 males) took part in Experiment 1 . The participants were aged $24(S D=4)$ years, were native, German speakers and reported no 
prior-known reading difficulties. Text was presented with full contrast $(99 \%$, calculated as Weber-contrast), that is, black text (luminance of $0.3 \mathrm{~cd} / \mathrm{m}^{2}$ ) was presented on a white background (luminance: of $48 \mathrm{~cd} / \mathrm{m}^{2}$ ). Each participant gave informed consent before the experiment; the research followed the tenets of the declaration of Helsinki and was approved by an internal ethics committee.

Stimuli and design. In Experiment 1, the set of 40 sentences (black letters on white background; see Figure 2a) was either presented binocularly or monocularly; when viewing was monocular, the non-reading eye was not presented with the text but with a blank screen that represented the homogenous white background (luminance of $48 \mathrm{~cd} / \mathrm{m}^{2}$ ). It was important to illuminate the eye which did not receive text input in order to avoid changes in pupil size, which in turn could cause changes in visual acuity (Howard, 2012). For the purpose of monocular presentations, we used a mirror stereoscope (Howard, 2002) with two half mirrors at a right angle and two TFT-LCD screens (thin film transistor liquid crystal displays). Monocular presentations were counterbalanced across the two eyes.

Insert Figure 2 around here

\section{Results}

Average sentence reading times increased from $2292 \mathrm{~ms}(S D=700)$ for binocular reading to $2425 \mathrm{~ms}(S D=786)$ for monocular reading $(b=74.75, S E=38.03, p=0.04)$. Mean fixation times also increased from $234 \mathrm{~ms}(S D=40$; binocular reading $)$ to $241 \mathrm{~ms}(S D=39)$ for monocular reading $(b=4.59, S E=2.22, p=0.04)$. The mean number of fixations $(M=10$; $S D=3)$ and regressions $(M=3 ; S D=2)$ within a sentence did not change (both $t$-values $<1)$ and (forward) saccade amplitudes remained unchanged as well $(M=2.18 \mathrm{deg} ; S D=0.49 ; t$ $<1$ ). Nevertheless, overall, this pattern of results showed a clear binocular reading advantage (see also, Jainta \& Jaschinski, 2012).

We then investigated the binocular advantage in lexical processing of the target word, which was either high or low word frequency. As in Jainta et al. (2014), we found a significant interaction between word frequency and binocular versus monocular reading in first fixation 
durations for the target word: we observed a very robust frequency effect of $70 \mathrm{~ms}$ under binocular reading conditions, while, under monocular reading conditions, we did not observe any reliable frequency effect $(b=-0.20, S E=0.04, p<0.01$; see Figure 3 and Table 1$)$. Furthermore, exactly as per the findings of Jainta et al. (2014), the frequency effect in the monocular viewing condition disappeared due to the reading times for the high frequency words increasing to be similar in duration to those for the low frequency words (see Figure 3). Insert Figure 3 and Table 1 around here

Calculating contrasts showed, that the word frequency effect in first fixation duration was significant for binocular reading $(b=0.22, S E=0.04, p<0.01)$, but non-significant for monocular reading of target words $(b=0.02, S E=0.03, p=0.56)$. This pattern of data was the same for gaze duration on the target word: overall, a two-way interaction $(b=-0.21, S E=$ $0.05, p<0.01)$ showed a difference in the word frequency effect between binocular (80 ms) and monocular reading $(20 \mathrm{~ms})$. Contrasts showed, that the word frequency effect in gaze duration was significant for binocular $(b=0.28, S E=0.04, p<0.01)$ but not for monocular reading $(b=0.06, S E=0.04, p=0.15)$. For total word reading times, binocular reading again showed a frequency effect of $81 \mathrm{~ms}$, and a smaller effect of word frequency of $32 \mathrm{~ms}$ in monocular reading (two-way interaction: $b=-0.21, S E=0.05, p<0.01$ ). This time, while the word frequency effect in binocular reading was again significant $(b=0.27, S E=0.04, p<0.01)$, the frequency effect in monocular reading showed a statistical tendency $(b=0.08, S E=0.04$, $p=0.06)$.

Next, we include another fixed effect to our LME-model, to test whether the interaction of word frequency and binocular versus monocular reading was further modulated by (a) the eye which was presented with the text (left eye versus right eye) or by (b) the dominant eye (dominant versus the non-dominant eye, see sighting test described above). When the eye was included into the analysis, for all three parameters the three-way-interaction was nonsignificant - first fixation duration $(b=0.04, S E=0.09, p=0.66)$, gaze duration $(b=0.06, S E$ $=0.10, p=0.55)$ and total reading time $(b=0.06, S E=0.11, p=0.58)$. The same was true for 
the analyses including eye dominance: neither first fixation duration $(b=0.05, S E=0.09, p=$ $0.57)$ nor gaze duration $(b=0.10, S E=0.11, p=0.37)$ nor total reading time $(b=0.09, S E=$ $0.11, p=0.44)$ showed a significant three-way-interaction. Thus, even though potentially interfering with the quality of visual processing (Howard, 2012; Leigh \& Zee, 2006; Schor \& Ciuffreda, 1983; Steinman, Steinman, \& Garzia, 2000) our data did not support any modulating effect of the dominant eye (or the eye which was presented with text) in monocular reading.

We clearly replicated our previous demonstrations of a binocular advantage in reading (Jainta et al., 2014; Jainta \& Jaschinski, 2012). We observed a general slowing in reading times when reading was monocular relative to when it was binocular. Furthermore, we replicated our binocular effects in relation to lexical processing. Efficient processing of a high frequency word (that is comparatively easy to identify), was substantially inhibited when words were read monocularly (Jainta et al., 2014) relative to when they were read binocularly. Next, in Experiment 2, we addressed the influence of contrast reduction on reading performance.

\section{Experiment 2}

In Experiment 2, we presented binocular text with full contrast $(99 \%$, calculated as Weber-contrast) and text that resembled monocular conditions in terms of contrast, that is, text with only approximately $70 \%$ of contrast. We did this to establish whether the cost to reading, and specifically to lexical identification, was due to reduced contrast under monocular viewing conditions. To re-iterate, the full contrast (99\%) resembled 1.4 times of the lower contrast $(70 \%)$ - and this reflects the increase in contrast which is needed to detect a monocularly presented stimulus as reliably as a binocularly presented stimulus (Blake \& Wilson, 2011; Howard, 2012). Note that this contrast reduction is less compared to previous studies and especially less than contrast reductions used by Sheridan and Reingold (2013), or Liu, Li and Han (2015), who reduced text contrast of a target word to $40 \%$ and $14 \%$, respectively. Further, it is important to note that monocular reading comes with a natural reduction in text contrast and that this reduction holds for the entire sentence (i.e. for each fixation). Therefore, we 
reduced the contrast for the whole sentence, which reflects a slightly different text manipulation in comparison to previous research.

Nevertheless, if text contrast impacts on reading performance (Drieghe, 2008; Glaholt, Rayner \& Reingold, 2014; Johansson, Pansell, Ygge, \& Seinmyr, 2014; Legge, Parish, Luebker, \& Wurm, 1990; Legge, Rubin, \& Luebker, 1987; Liu, Li \& Han, 2015; Paterson, McGowan \& Jordan, 2012; Reingold \& Rayner, 2006; Sheridan \& Reingold, 2013; Wang \& Inhoff, 2010; White \& Staub, 2012) and binocular advantages are due to altered contrast conditions in monocular reading, as hypothesized above, we predicted that a low text contrast of $70 \%$ should affect reading performance similar to the monocular text presentation in Experiment 1: reading times should be increased and the processing of high frequency words should be inhibited when compared to similar words under low contrast conditions. In contrast, if contrast manipulations additively affect word frequency effects (Liu, Li \& Han, 2015), or even increase word frequency effects, by slowing processing of low frequency words (Sheridan \& Reingold, 2013), then increased frequency effects alongside increased fixations for both high and low frequency words should occur.

\section{Methods}

Participants. 21 adults (12 females) took part in Experiment 2. The participants were aged $25(S D=3)$ years, were native, German speakers and reported no prior-known reading difficulties. Each participant gave informed consent before the experiment; the research followed the tenets of the declaration of Helsinki and was approved by an internal ethics committee.

Stimuli and design. The same procedures and stimuli of Experiment 1 were used in Experiment 2. The changes made were those necessitated by the change of text contrasts. The set of 40 sentences was always read binocularly, but the text was either presented as black letters on white background (high Weber-contrast: 99\%; same contrast calculated as Michelson-contrast would be $99 \%$; see Figure 1a) or as grey letters on white background (low Weber-contrast: $70 \%$; the same contrast calculated as Michelson-contrast would be about 
$55 \%$; see Figure $2 \mathrm{~b}$ ). To re-iterate, against a white background (luminance: of $48 \mathrm{~cd} / \mathrm{m}^{2}$ ) black, full contrast text appeared as black text (luminance: $0.3 \mathrm{~cd} / \mathrm{m}^{2}$ ), while low contrast text was appeared as grey text (luminance: $29 \mathrm{~cd} / \mathrm{m}^{2}$ ).

\section{Results}

When comparing all sentences, presented in either full contrast (99\% Weber-contrast) or in low contrast $(70 \%$ Weber-contrast), we observed no changes in reading behaviour: average sentence reading time was $2596 \mathrm{~ms}(S D=837)$ for full contrast presentations and $2609 \mathrm{~ms}(S D=813)$ for low contrast presentations $(t<1)$. Also, mean fixation time was 244 ms $(S D=44)$ for full contrast conditions and $245 \mathrm{~ms}(S D=43)$ for low contrast conditions $(t<$ 1). Neither mean saccade amplitude (full contrast: $M=2.02 \mathrm{deg}, S D=0.51$; low contrast: $M=$ $2.05 \mathrm{deg}, S D=0.53$ ) nor the mean number of fixations (full contrast: $M=9, S D=2$; low contrast: $M=9, S D=2$ ) or regressions (full contrast: $M=3, S D=2$; low contrast: $M=3, S D=$ 2) changed with different contrast presentations (all $t$-values $<1$ ). Thus, for global measures of reading performance no decrement in reading performance was observed.

When further analysing lexical processing of the target word, we found a strong word frequency effect regardless of the contrast condition: the data showed a robust main effect for word frequency for first fixation durations $(b=0.18, S E=0.04, p<0.01)$, gaze duration $(b=$ $0.17, S E=0.05, p<0.01)$ and total word reading time $(b=0.17, S E=0.05, p<0.01$; see Figure 4 and Table 2).

Insert Figure 4 and Table 2 around here

We then directly compared Experiment 1 and 2. To simplify matters, we will report only marginal or significant effects here: in the sentence level analyses, there was a tendency for average sentence reading time $(b=0.03, S E=0.02, p=0.09)$ and mean fixation time $(b=$ $0.10, S E=0.06, p=0.09)$ to be longer in Experiment 2 than in Experiment 1. This suggests that the lower contrast sentences in Experiment 2 were slightly more difficult to process than the full contrast sentences in Experiment 1, though this effect was not reliable. In contrast, for 
the local analyses of the target words, a three-way interaction (Experiment $x$ Reading condition $\mathrm{x}$ Word frequency) was significant for first fixation durations $(b=0.22, S E=0.04, p<0.01)$, gaze duration $(b=0.24, S E=0.08, p<0.01)$ and total word reading time $(b=0.21, S E=0.08$, $p<0.01$ ). When further calculating contrasts, none of the two-way interactions (experiment $x$ word frequency) were significant for binocular reading and full contrast conditions, respectively. However, first fixation durations showed a frequency effect in binocular reading with reduced contrast, but no word frequency effect in monocular reading (two-way interaction: $b=0.14, S E$ $=0.05, p<0.01$ ). The same held for gaze duration (two-way interaction: $b=0.14, S E=0.05$, $p<0.01$ ) and total word reading time (two-way interaction: $b=0.12, S E=0.06, p=0.03$ ). These results are extremely clear. Whilst monocular reading conditions resulted in a significant reduction in the efficacy of lexical identification processes during normal reading (as indexed by increased fixations durations on high frequency target words), word identification proceeded unhindered under reduced contrast reading conditions. A reasonable conclusion, therefore, is that the reduction in contrast that comes with monocular reading is not the factor that causes less efficient word identification.

\section{Interim discussion}

In Experiments 1 and 2 we reduced the contrast of the text. We achieved this in two ways. In Experiment 1 we presented sentences monocularly, thereby reducing contrast. In Experiment 2 we achieved a comparable contrast change through a simple contrast reduction of text that was presented binocularly. If these two reading situations produced comparable decrements to reading performance, we would have found similar results in both experiments. However, this was not the case. Monocular reading had small but robust effects on overall reading times, whereas contrast reductions to $70 \%$ produced less of a change - which is in line with previous research showing that contrast needs to be reduced substantially to affect reading performance (Drieghe, 2008; Glaholt, Rayner \& Reingold, 2014; Liu, Li \& Han, 2015; Paterson, McGowan \& Jordan, 2012; Reingold \& Rayner, 2006; Sheridan \& Reingold, 2013; Wang \& Inhoff, 2010; White \& Staub, 2012). More importantly, contrast did not contribute to 
the efficiency of reading in a way that binocular viewing conditions did. While clear frequency effects occurred during binocular reading and reading in full (99\%) and reduced (70\%) contrast conditions, no frequency effect was observed in monocular reading conditions. Thus, our contrast manipulation in Experiment 2 did not affect linguistic processing as a much as stronger contrast reductions of contrast (to $40 \%$ in Sherdian and Reingold, 2013 , or to $14 \%$ in Liu, Li and Han, 2015) did in previous research.

In sum, Experiment 2 shows two important results: (a) a reduction in contrast did not cause less efficient lexical lexical processing in the way that monocular viewing during reading did, and (b) although there was a slight increase in reading times for sentences under reduced contrast conditions, the effect was not reliable. Based on these results, we ran Experiment 3 in which we used a comparatively strong contrast reduction manipulation to (a) produce significantly increased reading times (as per previous studies), and (b) to assess whether stimuli with substantially reduced contrast applied to whole sentences (as monocular reading would do) caused diminished frequency effects as shown in Sheridan and Reingold (2013).

\section{Experiment 3}

In Experiment 3, we presented text with full (99\%) contrast or with reduced text contrast of about $40 \%$, i.e., a text contrast which should impact on visual processing with relation to the target word (Sheridan \& Reingold, 2013). We expected a general slowing in reading times under reduced contrast conditions and an increase in word frequency effect, that is, increased processing times for low frequency words relative to high frequency words. In other words, we hypothesized that this substantially reduced contrast manipulation would not impact on word identification as monocular reading does. It is important to note that monocular reading comes naturally with a reduction in text contrast and that this reduction holds for whole texts and presentations. Therefore, we reduced the contrast for the whole sentence, as we did in Experiment 2, which we note once more is a slightly different text manipulation to that employed in Sheridan and Reingold's study.

\section{Methods}


Participants. 20 adults ( 9 females) took part in Experiment 3 . The participants were aged $24(S D=3)$ years, were native, German speakers and reported no prior-known reading difficulties. Each participant gave informed consent before the experiment; the research followed the tenets of the declaration of Helsinki and was approved by an internal ethics committee.

Stimuli and design. The procedures and stimuli of Experiment 1 were used in Experiment 3. The changes made were those necessitated by the change of text contrasts. The set of 40 sentences was always read binocularly, but the text was either presented as black letters on white background (high Weber-contrast: 99\%; same contrast calculated as Michelson-contrast would be $99 \%$; see Figure 1a) or as grey letters on white background (low Weber-contrast: $40 \%$; same contrast calculated as Michelson-contrast would be about $28 \%$; see Figure 2c). To re-iterate, against a white background (luminance: of $48 \mathrm{~cd} / \mathrm{m}^{2}$ ) black, full contrast text appeared as black text (luminance: $0.3 \mathrm{~cd} / \mathrm{m}^{2}$ ) while a low contrast text appeared as grey text (luminance: $14 \mathrm{~cd} / \mathrm{m}^{2}$ ).

\section{Results}

In contrast to Experiment 2, when comparing all sentences with full contrast $(99 \%$ Weber-contrast) and low contrast (40\% Weber-contrast), we observed changes in reading times: average sentence reading time increased from $2444 \mathrm{~ms}(S D=824)$ for high contrast presentations to $2566 \mathrm{~ms}(S D=823)$ for low contrast presentations $(b=116.03, S E=41.36$, $p<0.01$ ). Mean fixation times also increased from $235 \mathrm{~ms}$ ( $S D=43$; full contrast) to $247 \mathrm{~ms}$ $(S D=43)$ for low contrast presentations $(b=12.01, S E=2.39, p<0.01)$. The mean number of fixations (full contrast: $M=8, S D=2$; low contrast: $M=9, S D=2$ ) and regressions (full contrast: $M=3, S D=2$; low contrast: $M=3, S D=2)$ within a sentence did not change $(t<1)$ and saccades amplitudes remained unchanged as well (full contrast: $M=2.11$ deg, $S D=0.51$; low contrast: $M=2.06 \mathrm{deg}, S D=0.52 ; t<1)$.

When analysing lexical processing of the target word in this experiment, we found a somewhat different pattern: the data showed a main effect of word frequency of $53 \mathrm{~ms}$ for first 
fixation durations $(b=0.19, S E=0.08, p<0.05$; see Figure 5 and Table 3$)$ and also a main effect for text contrast $(b=0.09, S E=0.03, p<0.05)$.

Insert Figure 5 and Table 3 around here

This pattern changed slightly for gaze duration on the target word: we found a significant main effect of $81 \mathrm{~ms}$ for word frequency $(b=0.24, S E=0.09, p<0.01)$ but only a tendency for a contrast main effect $(b=0.07, S E=0.04, p=0.07)$. For total word reading times, there was a $91 \mathrm{~ms}$ word frequency effect only $(b=0.21, S E=0.09, p<0.05)$.

We then directly compared Experiment 1 and 3. Again, we only report significant effects. For our sentence level analyses, average sentence reading time showed a tendency to be longer for monocular reading and reading with reduced contrast $(b=0.02, S E=0.02, p=0.09)$. Mean fixation time was substantially increased in both, monocular reading and low contrast conditions, compared to binocular reading $(b=0.02, S E=0.01, p=0.02)$. In the analyses of the fixation times on the target words, the three-way interaction (experiment $x$ reading condition $\mathrm{x}$ word frequency) was significant for first fixation durations $(b=0.19, S E=0.06, p<0.01)$, gaze duration $(b=0.20, S E=0.08, p<0.01)$ and total word reading time $(b=0.23, S E=0.08$, $p<0.01$ ). When further calculating contrasts, none of the two-way interactions (experiment $x$ word frequency) was significant for binocular reading and full contrast conditions. However, first fixation durations showed a word frequency effect in binocular reading with reduced contrast, but no such effect in monocular reading (two-way interaction: $b=0.13, S E=0.04, p$ $<0.01$ ). The same held for gaze duration (two-way interaction: $b=0.18, S E=0.05, p<0.01$ ) and total word reading time (two-way interaction: $b=0.21, S E=0.05, p<0.01$ ).

Finally, for completeness, we compared Experiments 2 and 3. For the sentence level analyses, mean fixation time showed significant two-way interaction $(b=0.04, S E=0.01, p<$ 0.01). Calculating contrasts showed that mean fixation time was only increased with reduced contrast in Experiment $3(b=0.05, S E=0.01, p<0.01)$ while it was unchanged in Experiment 2, as described above. For the fixation times on the target words, no interactions were 
significant. For first fixation times, two main effects occurred: a robust word frequency effect $(b$ $=0.17, S E=0.04, p<0.01)$ and an effect of reduced contrast $(b=0.08, S E=0.04, p=0.01)$. For gaze duration $(b=0.24, S E=0.04, p<0.01)$ and total word reading time $(b=0.26, S E=$ $0.05, p<0.01$ ) only main effects for word frequency occurred. Thus, even in direct comparison, we found a substantial cost to reading times for reduced contrast, but the pattern of effects is clearly different to that obtained for monocular presentations.

\section{Discussion}

Binocular reading generally comes with a binocular advantage (Heller \& Radach, 1998; Jainta et al., 2014; Jainta \& Jaschinski, 2012; Sheedy et al., 1986), that is, with shorter average fixation durations and total sentence reading times when compared to monocular reading (Jainta et al., 2014; Johansson et al., 2014). Monocular vision is generally an atypical viewing condition (for most people without binocular vision problems) and it typically comes with higher visual thresholds for luminance and contrast, for example (Blake \& Wilson, 2011; Howard, 2012).

In the present study we replicated previous findings that monocular presentation of sentences results in a cost to reading (Jainta et al., 2014; Jainta \& Jaschinski, 2012; Sheedy et al., 1986): Sentence reading times and average fixation durations increased under monocular viewing conditions. More specifically, as in Jainta et al. (2014), we found reduced word frequency effects under monocular reading due to high frequency words receiving longer processing times. This replication strongly supports the finding and conclusions about specific binocular advantages for lexical processing in reading, as discussed in Jainta et al. (2014).

Next, we examined whether such a binocular advantage might arise due to simple changes in contrast when presentations are monocular compared to binocular. In binocular reading, visual features, like luminance and contrast (as direct derivatives), are extracted and channelled in early visual processing on the basis of a combination of the two signals, one from each eye; this combination provides a richer source of visual information than that available from each eye alone and binocular advantages are traditionally thought to relate 
exclusively to an early signal summation advantage (Blake \& Wilson, 2011; Changizi, 2009; Howard, 2012; Leigh \& Zee, 2006; Schor \& Ciuffreda, 1983; Steinman et al., 2000). When reading is performed monocularly, early visual processing is based on just one visual signal coming from one eye, and consequently, no summation effects can occur and contrast thresholds, for example, increase as mentioned above (Blake \& Wilson, 2011; Changizi, 2009; Howard, 2012; Leigh \& Zee, 2006; Schor \& Ciuffreda, 1983; Steinman et al., 2000). Thus, binocular advantages in reading might be simply due to a contrast drop that comes naturally with changes from binocular to monocular reading, that is, changes that derive from the stimulus that is being visually processed. According to this hypothesis, we selected full and reduced contrast presentations in our second experiment such that the lower contrast resembled contrasts under monocular reading: the full contrast (99\%) resembled 1.4 times of the lower contrast $(70 \%)$, and therefore, the maximal difference in contrast thresholds when monocular and binocular viewing are compared (Blake \& Wilson, 2011; Howard, 2012). If contrast changes due to monocular presentations cause effects like those observed in Jainta et al. (2014), and the first experiment of this study, we should have seen comparable results in our second experiment. However, this was not the case: overall reading speed did not slow down significantly, and more importantly, a clear word frequency effect emerged across full and low contrast text presentations. This suggests that the effects reported by Jainta et al. (2014) and those in Experiment 1, were not caused by contrast changes alone, since simple reductions of contrast that resembled monocular conditions (i.e. 70\% contrast) in Experiment 2 did not affect word identification qualitatively in the way that monocular reading conditions did.

Previous reports, however, have shown impacts of visual input quality on early word recognition processes in reading (e.g., Pollatsek et al., 2006; Rayner et al., 2004; Reichle et al., 2013; Reichle et al., 2003; Reingold \& Rayner, 2006), demonstrating that reductions of text contrast cause fixation durations to increase considerably (Drieghe, 2008; Glaholt, Rayner \& Reingold, 2014; Johansson, Pansell, Ygge, \& Seinmyr, 2014; Legge, Parish, Luebker, \& Wurm, 1990; Legge, Rubin, \& Luebker, 1987; Liu, Li \& Han, 2015; Paterson, McGowan \& 
Jordan, 2012; Reingold \& Rayner, 2006; Sheridan \& Reingold, 2013; Wang \& Inhoff, 2010; White \& Staub, 2012). In line with previous research, we found a clear cost to sentence reading time due to contrast reduction in Experiment 3, in which we presented text in full (99\%) and low contrast $(40 \%)$, that is, a substantial manipulation of contrast. In fact, the overall pattern of reading performance when evaluated at the sentence level was similar to monocular reading; both manipulations slowed reading times and increased fixation durations. As mentioned above, such results fit neatly with current understanding that visual input quality impacts on early word recognition processes in reading. These effects can also be explained within an interactive activation framework (McClelland \& Rumelhart, 1981; Rumelhart \& McClelland, 1982), where introducing stimulus quality degradation by means of reducing contrast impairs feature extraction during lexical processing. Such impairment at the visual processing level can then result in a delay of lexical processing that is comparable for both high frequency and low frequency words. Additionally, this observation fits neatly with computational models of eye movement control during reading (e.g. E-Z Reader, Reichle et al. 2003, 2013; Pollatsek et al., 2006), whereby the visual quality of the text can influence fixation durations either at an early lexical processing stage or at an even earlier, pre-lexical visual encoding stage (see Reingold \& Rayner, 2006; Sheridan \& Reingold, 2012; White \& Staub, 2012 for further discussion of the specific locus of the effect). Critically, however, in Experiment 3 the word frequency effect was clearly present and statistically reliable even under the low (40\%) contrast conditions. This finding is in line with previous reports by Sheridan and Reingold (2013). However, while they showed a clear interactive effect (i.e. longer processing for low-frequency but not high-frequency target words presented with reduced contrast), we report an additive effect (i.e. increased fixation durations for both high-frequency and low-frequency target words). It is important to note that although our contrast manipulation in Experiment 3 was similar to the manipulation used in Sheridan and Reingold (2013), there was one critical distinction: our contrast manipulations in Experiment 2 and 3 were applied to the whole text, while Sheridan and Reingold (2013) only changed the contrast of a single target word. It is well documented in both psychophysiological and neuroimaging studies that the perceived contrast 
of a central visual stimulus can be altered by the contrast of peripheral stimuli (Levitt \& Lund, 1997; Xing \& Heeger, 2000). We therefore purposefully manipulated contrast for the entire sentence to mimic changes which come naturally during each fixation in monocular reading and avoid the possibility of attention being drawn to a single low-contrast parafoveal target. Our present finding is more in line with reports of Lui, Li and Han (2015), who reported additive effects of word frequency and reduced contrast for Chinese reading. These authors reduced the contrast of a single word but to a much greater degree, i.e. down to $14 \%$. We speculate that changing the contrast for the whole presentation might impact on general visual processing efficiency and, as a consequence, enhance effects of contrast degradation. Therefore, it might be the case that our results in Experiment 3 (showing additive effects of text contrast reduction to $40 \%$ ) resemble those reported for stronger contrast reductions (to $14 \%$ ) of a single target word. Further research is needed to test these speculations. Nevertheless, even when the contrast manipulation caused disruption to reading as evidenced by global eye movement measures, lexical processing was qualitatively different between conditions of reduced contrast and monocular visual presentation. Thus, it seems unlikely that the reduced contrast caused the modulation of the frequency effect reported by Jainta et al. (2014), and observed in Experiment 1.

Having demonstrated that variations in text contrast alone cannot account for the specific binocular advantages for lexical processing that we observed, it is important to consider the potential origin of such effects. Note that the subjective reports from our participants revealed dissociation between perceptual experience and reading performance similar to that reported by Jainta et al., (2014). While contrast changes during binocular presentation conditions were immediately detected, participants could not discriminate between a binocular and a monocular visual presentation. This experimental effect can be easily demonstrated in an everyday example: closing or covering one eye makes no great difference to the visual quality of this page, whereas reducing the brightness of the monitor has an immediate effect on the ease with which the text is distinguished from the background. 
This discrepancy seems to suggest that during reading the two manipulations reduced contrast and monocular presentation - exert their effects on different levels of text processing. What is apparent from our findings and from those of Reingold \& Rayner, (2006), Sheridan and Reingold, (2012) and White and Staub, (2012) is that a manipulation of stimulus quality influences the visual processing system and the speed with which visual features can be extracted and encoded in order to be delivered to the lexical processing system. When text is presented to one eye instead of two, no differences in visual quality were perceived by participants presumably because the monocular presentation did not exert its effect at the level of visual encoding. Instead, it appears that it qualitatively changes the capacity with which the cognitive systems that process visual information after it has been encoded can operate. In the case of reading, it appears that the efficiency of function of the linguistic processing system, and specifically, the lexical processor, is dramatically reduced.

A potential underlying mechanism for this effect is the facilitation of activation at the cortical level for binocular relative to monocular stimuli. Neurons in the visual cortex are functionally specialised among many categories, such as sensitivity to colour, motion or depth. There is also a continuum of cells across cortical layers from those that respond exclusively to monocular stimuli to those that receive balanced input from both eyes (e.g., Hubel \& Wiesel, 1968). These binocular and monocular neurons may be considered as different neural populations. Furthermore, many binocular depth cells respond either very little or not at all to stimulation from each eye alone (Hubel \& Wiesel, 1970). As a consequence of this, binocular presentation results in the activation of a larger number of neuronal populations in the visual cortex than monocular presentation. Previous research in humans has indeed reported an increase in the number of responding neurons and in the amplitude for visual evoked potentials for binocular relative to monocular stimuli (Pardhan, Gilchrist \& Douthwaite, 1990; Skrandies, 1993; though see Nakayama, Apkarian, \& Tyler, 1982 for discussion of the role of spatial frequency).

In the context of reading, it is possible that the activation within these neuronal populations influences the efficiency of lexical processing. This might create three very distinct 
scenarios for binocular presentation, reduced contrast presentation and monocular presentation. We present them schematically in Figure 6, and next we work through an illustrative example of how this account may explain our effects. If we assume that during binocular presentation, for example, 1000 cells respond to the stimulus with optimal levels of activation, then we can group them in five (somewhat arbitrary) categories, according to the relative effectiveness of each eye. Based on existing animal models (Cumming \& Parker, 1997; Hubel \& Livingstone, 1987), we assume that binocular cells are common in the visual cortex and that each eye is roughly equally represented. Furthermore, in macaques, binocular and monocular cells are about equally common, but many binocular cells strongly favour one eye. Figure 6 illustrates that under binocular conditions of both full and reduced contrast, the same number of cells respond to the stimulus, but with reduced strength of activation, as determined by the level of contrast. In fact, functional imaging findings from Avidan, Harel, Hendler, BenBashat, Zohary and Malach (2002) demonstrated that, as long as contrast levels were above discrimination threshold, object recognition performance did not improve with an increase in contrast and there was a trend for contrast invariance with respect to the neural activation in higher-order areas of the visual cortex. In comparison, when visual presentation is monocular, the level of activation remains unchanged, but only approximately half of the cells respond to the stimulus since only one visual receptor receives stimulation.

To be clear, what we are suggesting is that this reduced neural activation feeds into the lexical processing system, and the reduced activation in turn results in a processing delay that is particularly evident for high frequency words. One potential reason why this effect is particularly evident for high frequency and not low frequency words (in first-pass reading measures) is that during sentence processing, the optimal behavioural strategy for readers is to rapidly move their eyes from one word to the next in order to encode new information. Therefore, under monocular viewing conditions where reading is more difficult than binocular viewing conditions, when a low frequency word is encountered, which itself causes additional processing difficulty, it is unlikely that the reader would pause and maintain fixation on that word until the difficulty is fully resolved. That is to say, there is a critical time period during 
which a reader will process a word, and after this period has elapsed, they will make a saccade to reposition the eye, either forward to upcoming text or regressively to previously read text (see also Jainta et al., 2014). Because in the case of low frequency words lexical identification times are already at ceiling, this time period may not be sufficient to allow for additionally extended fixations reflecting disruption due to reduced activation. In other words, it is likely that the effect is spread over many measures of processing difficulty. Indeed, in our data, we find a numerical increase in the number of fixations, regressions and total reading times for the target word, as well as a significant increase in average fixation duration. All these different behavioral responses to difficulty result in a statistically robust increase in total sentence reading times for monocular presentation conditions, and reflect the reduced processing capacity of the lexical identification system, which results from the overall decrease in neural activation during monocular presentations.

A further explanation can be provided by similar findings within the aural domain that have been reported by Endrass, Mohr and Pulvermüller (2004). They investigated the difference in neural activation elicited by spoken words and pseudowords presented monaurally (only to the left or only to the right ear) and binaurally (to both ears). Their findings indicated that an increase in brain activity could be found for familiar words presented binaurally rather than monaurally. In contrast, no such binaural advantage was found for pseudowords (i.e. unknown, meaningless stimuli). Endrass et al. (2004) concluded that because familiar, learned stimuli are represented by neuronal ensembles (memory traces) distributed over both hemispheres, a binaural stimulation results in a summation of neuronal activity across those ensembles. That is, during a binaural presentation the memory traces for familiar stimuli receive twice the activation, resulting in an enhanced neural response. In contrast, the neural activation elicited by unfamiliar, meaningless stimuli does not differ between binaural and monaural stimulation because no neuronal ensambles (memory traces) exist to represent such stimuli, and therefore no summation effects can occur.

Analogous to a monaural auditory presentation, a monocular visual presentation may result in a decrease in processing capacity within the lexical identification system. In reading, 
high frequency words (i.e.very familiar stimuli) are well represented, whereas low frequency words, because they are less familiar by definition, may be thought of as less strongly represented within the lexical identification system. Monocular reading comes with reduced neural activation (Pardhan, Gilchrist \& Douthwaite, 1990; Skrandies, 1995), which is somewhat analogous to reduced activation due to monaural presentation of linguistic stimuli (Endrass et al., 2004). It is important to note, however, that foveal visual inputs (in contrast to auditory inputs) do always project to both cortical hemispheres, regardless of monocular or binocular presentations. Nevertheless, it seems reasonable to suggest that high frequency words may benefit from enhanced neural activation under binocular reading while low frequency words may not. In other words, it may be the case that increased levels of activation within the lexical processing system (i.e., increased neural activity) are required in order that representations corresponding to high frequency words become sufficiently activated to allow lexical identification to occur with maximum efficiency. In comparison, low frequency words - similar to unfamiliar stimuli in Endrass et al.'s (2014) account - may not benefit as much from neural activation effects during binocular reading. Therefore, any changes in absolute activation within their representations would not reduce the efficiency with which they are identified during monocular reading to a comparable degree.

To summarize, it should be clear that in our view the effects that we observed on the target word arose due to less efficient word identification that itself was likely caused by reduced neuronal activation. It may be possible to derive an alternative account in which the effects arise due to differences in saccade generation between binocular and monocular reading that are independent of lexical identification. For example, reduced neural activation in monocular reading may have its impact on oculomotor mechanisms, rather than linguistic (lexical) processing systems. In our view, however, any such explanation seems quite unlikely since it would require that the very direct and immediate linkage between ongoing cognitive processing and oculomotor control in reading (i.e., saccade generation, see Rayner 1998; Liversedge \& Findlay, 2000) would be severed, or at best delayed, in monocular presentation conditions. It is not quite clear how eye movement behaviour would have any relation to 
reading processes under such circumstances. Furthermore, given that participants were insensitive to changes in the quality of their perceptual experience under monocular relative to binocular viewing conditions, it is not clear what justification could be provided for such breakdown of the core underlying principles of models of oculomotor control in reading during monocular presentations.

In conclusion, the present series of experiments demonstrates an important distinction between monocular reading and binocular reading of text with reduced contrast. Our findings suggest that a monocular presentation causes no drastic reduction in stimulus quality, but instead affects processing efficiency within the lexical identification system. This suboptimal mode of operation, which derives from the overall reduction in neural activation during monocular reading, results in a decrease in efficiency when processing highly familiar stimuli (high freqeuncy words), but no observable corresponding decrease for less familiar stimuli (low frequency words). Binocular advantages for lexical processing do not, therefore, arise as a direct consequence of changes in stimulus contrast, but instead originate from differences in the optimality of the performance of the system responsible for lexical identification in a monocular relative to a binocular mode of operation. These results demonstrate the importance of high-precision binocular vision for efficient lexical processing and further indicate that the complex interplay between the human visual system and the language processing system is crucial for effective reading performance. 


\section{References}

Avidan, G., Harel, M., Hendler, T., Ben-Bashat, D., Zohary, E., \& Malach, R. (2002). Contrast sensitivity in human visual areas and its relationship to object recognition. Journal of Neurophysiology, 87, 3102-3116.

Baayen, R. H., Davidson, D. J., \& Bates, D. M. (2008. Mixed-effects modeling with crossed random effects for subjects and items. Journal of Memory and Language, 59, 390412.

Baayen, R., Piepenbrock, R. \& Gulikers, L. (1995). CELEX2 LDC96L14. Web Download. Philadelphia: Linguistic Data Consortium.

Blake, R., Sloane, M., \& Fox, R. (1981). Further developments in binocular summation. Perception \& Psychophysics, 30(3), 266-276.

Blake, R., \& Wilson, H. (2011). Binocular vision. Vision Res, 5177), 754-770.

Changizi, M. (2009). The Vision Revolution: How the Latest Research Overturns Everything We Thought We Knew About Human Vision. Dallas: BenBella.

Cumming B.G., \& Parker A.J. (1997). Responses of primary visual cortical neurons to binocular disparity without the perception of depth. Nature, 389, 280 283.

Drieghe, D. (2008). Foveal processing and word skipping during reading. Psychonomic Bulletin \& Review, 15, 856-860.

Ehrenstein, W.H., Arnold-Schulz-Gahmen, B.E. \& Jaschinski, W. (2005). Eye preference within the context of binocular functions. Graefes Arch. Exp. Ophthalmol., 243, 926932.

Endrass, T., Mohr, B., \& Pulvermüller, F. (2004). Enhanced mismatch negativity brain response after binaural word presentation. European Journal of Neuroscience, 19, $1653-1660$. 
Engbert, R., Longtin, A., \& Kliegl, R. (2002). A dynamical model of saccade generation in reading based on spatially distributed lexical processing. Vision Research, 42, 621636.

Engbert, R., Nuthmann, A., Richter, E. M., \& Kliegl, R. (2005). SWIFT: A dynamical model of saccade generation during reading. Psychological Review, 112, 777-813.

Evans, J.R. (2002). Pickwell's Binocular Vision Anomalies. London: Butterworth.

Glaholt, M.G., Rayner, K. \& Reingold, E.M. (2014). A rapid effect of stimulus quality on the durations of individual fixations during reading. Visual Cognition, 22, 377-389.

Heller, D., \& Radach, R. (1998). Eye movements in reading: Are two eyes better than one? Current oculomotor research: Physiological and psychological aspects.

Howard, I. P. (2002). Seeing in Depth; Basic Mechanisms (Vol. 1). Toronto, Canada: Porteous, I.

Howard, I. P. (2012). Perceiving in Depth. Oxford, New York: Oxford University Press.

Hubel D. H., \& Livingstone M. S. (1987). Segregation of form, color, and stereopsis in primate area 18. Journal of Neuroscience, 7,3378 3415.

Hubel, D. H., \& Wiesel, T. N. (1968). Receptive fields and functional architecture of monkey striate cortex. Journal of Physiology, 195, 215-243.

Hubel, D. H., \& Wiesel, T. N. (1970). Stereoscopic vision in macaque monkey. Cells sensitive to binocular depth in area 18 of the macaque monkey cortex. Nature, 225, 41-43.

Inhoff, A. W., \& Rayner, K. (1986). Parafoveal word processing during eye fixations in reading: Effects of word frequency. Perception \& Psychophysics, 4066), 431-439.

Jainta, S., Blythe, H. I., \& Liversedge, S. P. (2014). Binocular Advantages in Reading. Current Biology, 24, 526-530. 
Jainta, S., Dehnert, A., Heinrich, S. P., \& Jaschinski, W. (2011). Binocular coordination during reading of blurred and non-blurred text. Investigative Ophthalmology and Visual Science. doi:10.1167/iovs.11-8237

Jainta, S., Hoormann, J., Kloke, W. B., \& Jaschinski, W. (2010). Binocularity during reading fixations: Properties of the minimum fixation disparity. Vision Research, 50, 17751785.

Jainta, S., \& Jaschinski, W. (2012). Individual differences in binocular coordination are uncovered by directly comparing monocular and binocular reading conditions. . Invest Ophthalmol Vis Sci, 53, 5762-5769.

Johansson, J., Pansell, T., Ygge, J., \& Seinmyr, G. O. (2014). The effect of contrast on monocular versus binocular reading performance. Journal of Vision, 14(5), 1-14.

Jordan, T. R., McGowan, V. A., \& Paterson, K. B. (2012). Reading with a filtered fovea: The influence of visual quality at the point of fixation during reading. Psychonomic Bulletin \& Review, 19, 1078-1084.

Kirkby, J. A., Webster, L. A., Blythe, H. I., \& Liversedge, S. P. (2008). Binocular coordination during reading and non-reading tasks. Psychol Bull, 134(5), 742-763.

Kliegl, R., Nuthmann, A., \& Engbert, R. (2006). Tracking the mind during reading: The influence of past, present, and future words on fixation durations. J Exp Psychol Gen, $135,12-35$.

Kwon, M., \& Legge, G. E. (2012). Spatial-frequency requirements for reading revisited. Vision Research, 62, 139-147.

Legge, G. E., Parish, D. H., Luebker, A., \& Wurm, L. (1990). Psychophysics in reading. XI. Comparing color contrast and luminance contrast. Journal of the Optical Society of America A, Optics and Image Science, 7, 2002-2010. 
Legge, G. E., Pelli, D. G., Rubin, G. S., \& Schleske, M. M. (1985). Psychophysics of reading - I. Normal vision. Vision Research, 25, 239-252.

Legge, G. E., Rubin, G. S., \& Luebker, A. (1987). Psychophysics of reading - V. The role of contrast in normal vision. Vision Research, 27, 1165-1177.

Leigh, R. J., \& Zee, D. S. (2006). The neurology of eye movements (4th ed. ed.). New York: Oxford University Press.

Levitt, J. B., \& Lund, J. S. (1997). Contrast dependence of contextual effects in primate visual cortex. Nature, $387(6628), 73 \cdot 76$.

Liu, P., Li, X. \& Han, B. (2015). Additive effects of stimulus quality and word freqeuncy on eye movements during Chinese reading. Reading and Writing, 28, 199-215.

Liversedge, S. P., Rayner, K., White, S. J., Findlay, J. M., \& McSorley, E. (2006). Binocular coordination of the eyes during reading. Current Biology, 16(17), 1726-1729.

Liversedge, S. P., White, S. J., Findlay, J. M., \& Rayner, K. (2006). Binocular coordination of eye movements during reading. Vision Research, 46(15), 2363-2374.

Mapp, A.P., Ono, H. \& Barbeito, R. (2003). What does the dominant eye dominate? A brief and somewhat contentious review. Percept. Psychophys., 65, 310-317.

McClelland, J. L., \& Rumelhart, D. E. (1981). An Interactive Activation Model of Context Effects in Letter Perception: Part 1. An Account of Basic Findings. Psychological Review, 88(5), 375-407.

Pardhan, S., Gilchrist, J., \& Douthwaite, W. (1990). Binocular Inhibition: Psychophysical and Electrophysiological Evidence. Optometry and Vision Science, 67, 688-691.

Paterson, K. B., McGowan, V. A., \& Jordan, T. R. (2013). Filtered text reveals adult age differnces in reading: Evidence from eye movements. Psychology and Aging, 28, $352-364$ 
Paterson, K. B., McGowan, V. A., \& Jordan, T. R. (2012). Eye movements reveal effects of visual context on eye guidance and lexical access during reading. PLoS ONE, 7(8), e41766.

Pinheiro, J. C., \& Bates, D. M. (2000). Mixed-Effects Models in S and S-Plus. New York: Springer.

Pollatsek, A., Reichle, E. D., \& Rayner, K. (2006). Tests of the E-Z Reader model: Exploring the interface between cognition and eye movement control. Cognitive Psychology, $52,1-56$.

R-Development-Core-Team. (2008). R: A Language and Environment for Statistical Computing: (< http: //www.R-project.org >).

Rayner, K. (1998). Eye movements in reading and information processing: 20 years of research. Psychol Bull, 124(3), 372-422.

Rayner, K., Ashby, J., Pollatsek, A., \& Reichle, E. D. (2004). The effects of Frequency and Predictability on Eye Fixations in Reading: Implications for the E-Z Reader Model. Journal of Experimental Psychology, Human Perception \& Performance, 30, 720732.

Rayner, K., \& Duffy, S. A. (1986). Lexical complexity and fixation times in reading: Effects of word freqeuncy, verb complexitiy, and lexical ambiguity. Memory and Cognition, 14, 191-201.

Rayner, K., Liversedge, S. P., White, S. J., \& Vergilino-Perez, D. (2003). Reading disappearing text. Psychological Science, 14, 385-388.

Reichle, E. D., Liversedge, S. P., Drieghe, D., Blythe, H. I., Joseph, H. S., White, S. J., \& Rayner, K. (2013). Using E-Z Reader to examine the concurrent development of eyemovement control and reading skill. Developmental Review, 33, 110-149. 
Reichle, E. D., Rayner, K., \& Pollatsek, A. (2003). The E-Z Reader model of eye-movement control in reading: Comparison to other models. Behavioral and Brain Sciences, 26, 445-526.

Reingold, E. M., \& Rayner, K. (2006). Examining the word identification stages hypothesized by the E-Z Reader model. Psychological Science, 17, 742-746.

Richter, E. M., Engbert, R., \& Kliegl, R. (2006). Current advances in SWIFT. Cognitive Systems Research, 7, 23-33.

Rumelhart, D. E., \& McClelland, J. L. (1982). An Interactive Activation Model of Context Effects in Letter Perception: Part 2. The Contextual Enhancement Effect and Some Tests and Extensions of teh Model. Psychological Review, 89(1), 60-94.

Schor, C. M., \& Ciuffreda, K. J. (1983). Vergence Eye Movements: Basic and Clinical Aspects. Boston: Butterworths.

Sheedy, J. E., Bailey, I. L., Buri, M., \& Bass, E. (1986). Binocular vs. monocular task performance. American Journal of Optometry and Physiological Optics, 63(10), 839 846.

Sheridan, H. \& Reingold, E.M. (2013). A further examination of the lexical-processing stages hypothesized by the E-Z Reader model. Attention, Perception \& Psychophysics, 75, 407-414.

Skrandies, W. (1995). Visual information processing: topography of brain electrical activity. Biological Psychology, 40, 1-15.

Steinman, S. B., Steinman, B. A., \& Garzia, R. P. (2000). Foundations of binocular vision. NewYork: The MacGraw-Hill Companies.

Venables, W. N., \& Smith, D. M. (2001). An Introdcution to R. 
Wang, C.A. \& Inhoff, A.W. (2010). The influence of visual contrast and cae changes on parafoveal preview benefits during reading. Quarterly Journal of Experimental Psychology, 63, 805-817.

White, S.J. \& Staub, A. (2012). The distribution of fixation durations during reading: Effects of stimulus quality. Journal of Experimental Psychology: Human Perception and Performance, 38, 603-617.

Xing, J., \& Heeger, D. J. (2000). Center ' surround interactions in foveal and peripheral vision. Vision Research, 40, 3065 ' 3072. doi:10.1016/S0042-6989(00)00152-8 
Tables:

Table 1

Linear-mixed effect models for first fixation duration, gaze duration and total reading time (ms) on the target word in Experiment 1. Both measures were log-transformed for normalization prior to analysis.

\begin{tabular}{|c|c|c|c|c|c|c|c|c|c|c|c|c|}
\hline \multirow[t]{2}{*}{ Fixed Factor } & \multicolumn{4}{|c|}{ Log (First Fixation Duration) } & \multicolumn{4}{|c|}{ Log (Gaze Duration) } & \multicolumn{4}{|c|}{ Log (Total Reading Time) } \\
\hline & $b$ & $S E$ & $t$ & & $b$ & $S E$ & $t$ & & $b$ & $S E$ & $t$ & \\
\hline (Intercept) & 5.39 & 0.03 & 167.89 & $* * *$ & 5.50 & 0.03 & 138.52 & $* * *$ & 5.51 & 0.04 & 133.54 & $* * \star$ \\
\hline $\begin{array}{l}\text { Reading: } \\
\text { Binocular vs. } \\
\text { Monocular (BM) }\end{array}$ & 0.25 & 0.03 & 7.96 & $* * *$ & 0.23 & 0.04 & 6.64 & $* * *$ & 0.22 & 0.04 & 5.86 & $* * *$ \\
\hline $\begin{array}{l}\text { Target Word } \\
\text { Frequency: } \\
\text { Low vs. High } \\
\text { (WF) }\end{array}$ & 0.22 & 0.03 & 6.76 & $* \star \star$ & 0.27 & 0.04 & 6.32 & $* * *$ & 0.28 & 0.04 & 6.29 & $* * *$ \\
\hline$B M \times W F$ & -0.20 & 0.04 & -4.51 & $* * *$ & -0.21 & 0.05 & -4.00 & $* \star *$ & -0.18 & 0.05 & -3.50 & $* * *$ \\
\hline
\end{tabular}

Note: ${ }^{* *}: p \leq 0.001,{ }^{* *}: p \leq 0.01,{ }^{*}: p \leq 0.05,{ }^{+}: p \leq 0.10$ 


\section{Table 2:}

Linear-mixed effect models for first fixation duration, gaze duration and total reading time (ms) on the target word in Experiment 2. Both measures were log-transformed for normalization prior to analysis.

\begin{tabular}{|c|c|c|c|c|c|c|c|c|c|c|c|c|}
\hline \multirow[t]{2}{*}{ Fixed Factor } & \multicolumn{4}{|c|}{ Log (First Fixation Duration) } & \multicolumn{4}{|c|}{ Log (Gaze Duration) } & \multicolumn{4}{|c|}{ Log (Total Reading Time) } \\
\hline & $b$ & $S E$ & $t$ & & $b$ & $S E$ & $t$ & & $b$ & $S E$ & $t$ & \\
\hline (Intercept) & 5.36 & 0.04 & 144.17 & $\star \star * *$ & 5.53 & 0.04 & 134.46 & *** & 5.53 & 0.04 & 134.55 & *** \\
\hline $\begin{array}{l}\text { Reading: } \\
\text { High vs. Low } \\
\text { Contrast (C50) }\end{array}$ & 0.03 & 0.04 & 0.94 & & -0.01 & 0.04 & -0.23 & & -0.01 & 0.04 & -0.21 & \\
\hline $\begin{array}{l}\text { Target Word } \\
\text { Frequency: } \\
\text { Low vs. High } \\
\text { (WF) }\end{array}$ & 0.18 & 0.04 & 4.32 & $* * *$ & 0.17 & 0.04 & 5.58 & $* * *$ & 0.17 & 0.05 & 3.64 & *** \\
\hline C50 x WF & -0.02 & 0.05 & -0.37 & & 0.04 & 0.06 & 0.68 & & 0.03 & 0.06 & 0.51 & \\
\hline
\end{tabular}

Note: ${ }^{* * *}: p \leq 0.001,{ }^{* *}: p \leq 0.01,{ }^{*}: p \leq 0.05,{ }^{*}: p \leq 0.10$ 


\section{Table 3:}

Linear-mixed effect models for first fixation duration, gaze duration and total reading time (ms) on the target word in Experiment 3. Both measures were log-transformed for normalization prior to analysis.

\begin{tabular}{|c|c|c|c|c|c|c|c|c|c|c|c|c|}
\hline \multirow[t]{2}{*}{ Fixed Factor } & \multicolumn{4}{|c|}{ Log (First Fixation Duration) } & \multicolumn{4}{|c|}{ Log (Gaze Duration) } & \multicolumn{4}{|c|}{ Log (Total Reading Time) } \\
\hline & $b$ & $S E$ & $t$ & & $b$ & $S E$ & $t$ & & $b$ & $S E$ & $t$ & \\
\hline (Intercept) & 5.28 & 0.06 & 85.92 & $* * *$ & 5.42 & 0.07 & 77.46 & $* * *$ & 5.43 & 0.07 & 76.92 & *** \\
\hline $\begin{array}{l}\text { Reading: } \\
\text { High vs. Low } \\
\text { Contrast (C26) }\end{array}$ & 0.09 & 0.03 & 2.53 & * & 0.07 & 0.04 & 1.75 & + & 0.07 & 0.04 & 1.67 & + \\
\hline $\begin{array}{l}\text { Target Word } \\
\text { Frequency: } \\
\text { Low vs. High } \\
\text { (WF) }\end{array}$ & 0.19 & 0.08 & 2.34 & * & 0.24 & 0.09 & 2.61 & ** & 0.21 & 0.09 & 2.21 & * \\
\hline C26 x WF & -0.01 & 0.05 & -0.24 & & 0.01 & 0.06 & 0.09 & & 0.04 & 0.06 & 0.79 & \\
\hline
\end{tabular}

Note: ${ }^{* *}: p \leq 0.001,{ }^{* *}: p \leq 0.01,{ }^{*}: p \leq 0.05,{ }^{+}: p \leq 0.10$ 
Figures:

Figure 1: Sentences frames contained a high (Haarband) or low frequency (Mikrofon) target word.

Das Mädchen hatte ihr neues Haarband hinter der Bühne verloren.

Das Mädchen hatte ihr neues Mikrofon hinter der Bühne verloren. 
Figure 2: Sentences were presented in high contrast (a; 99\% Weber-Contrast) in Experiment 1, but also monocularly or binocularly. In Experiment 2 sentences were presented in high (a; $99 \%$ ) or with a lower contrast of $70 \%$ Weber-Contrast, while in Experiment 3 sentences were presented either in high contrast (a; 99\%) or with an even lower contrast compared to Experiment 2, that is, with a contrast of $40 \%$ Weber-Contrast (c).
(a) Das Mädchen hatte ihr neues Haarband hinter der Bühne verloren.
(b) Das Mädchen hatte ihr neues Haarband hinter der Bühne verloren.
(c) Das Mädchen hatte ihr neues Haarband hinter der Bühne verloren. 
Figure 3: First fixation duration (ms), gaze duration (ms) and total word reading time (ms) for target words of high and low frequency in Experiment 1. Means ( \pm SE) are also separated for binocular and monocular presentations, respectively.

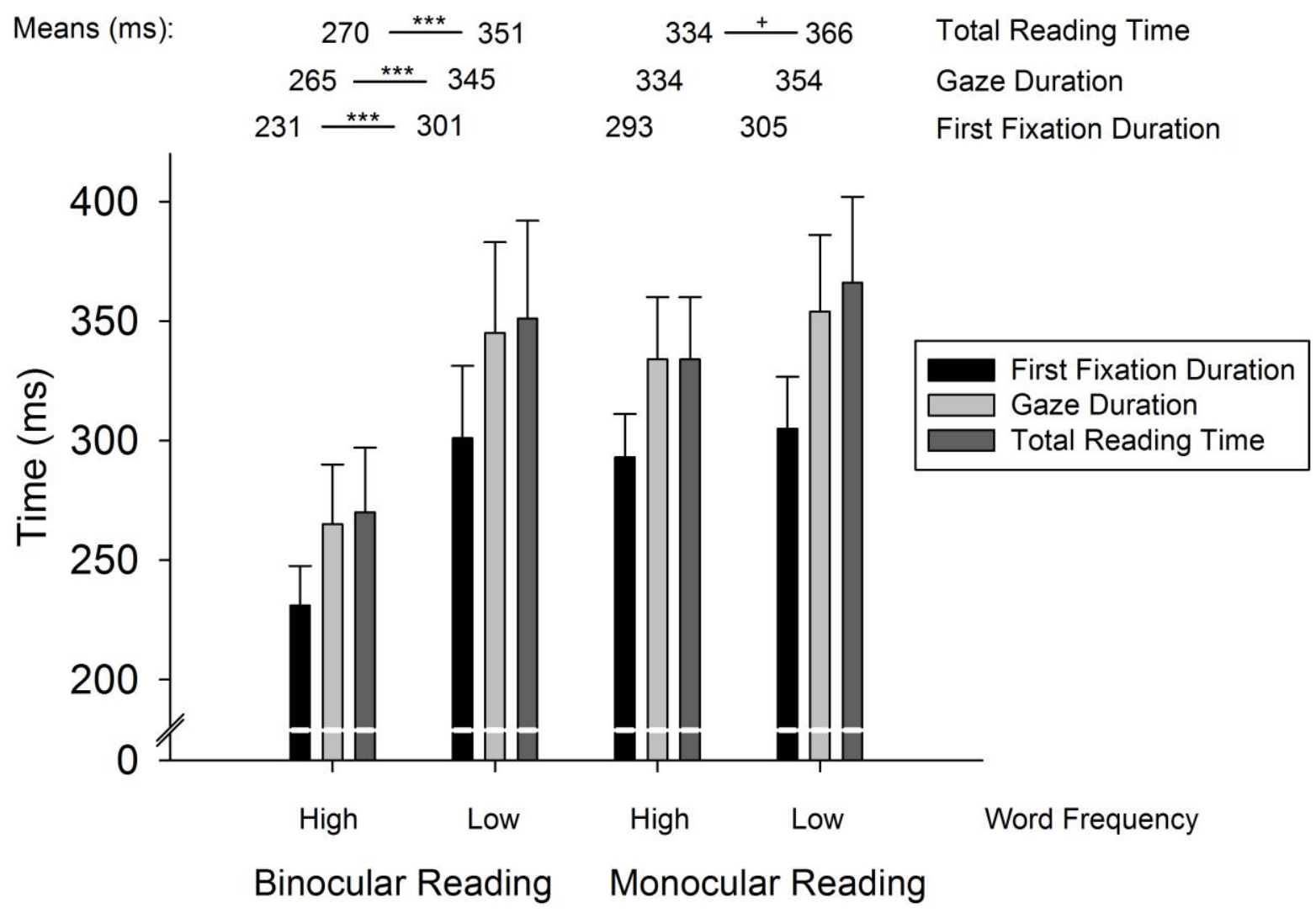


Figure 4: First fixation duration (ms), gaze duration (ms) and total word reading time (ms) for target words of high and low frequency in Experiment 2. Means ( \pm SE) are also separated for high contrast (99\%) and low contrast (70 \%) presentations, respectively.

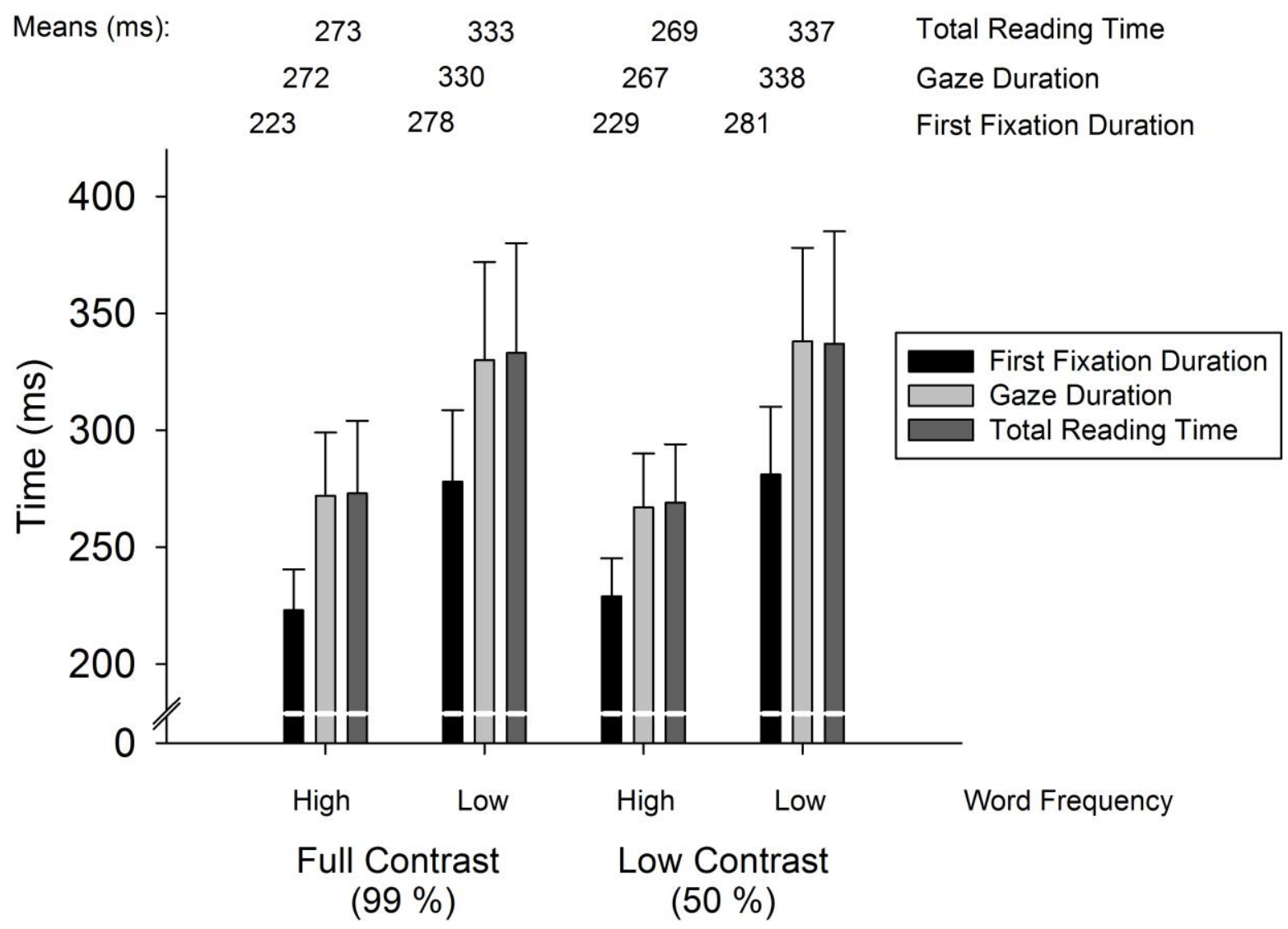


Figure 5: First fixation duration (ms), gaze duration (ms) and total word reading time (ms) for target words of high and low frequency in Experiment 3. Means ( \pm SE) are also separated for high contrast (99\%) and low contrast (40\%) presentations, respectively.

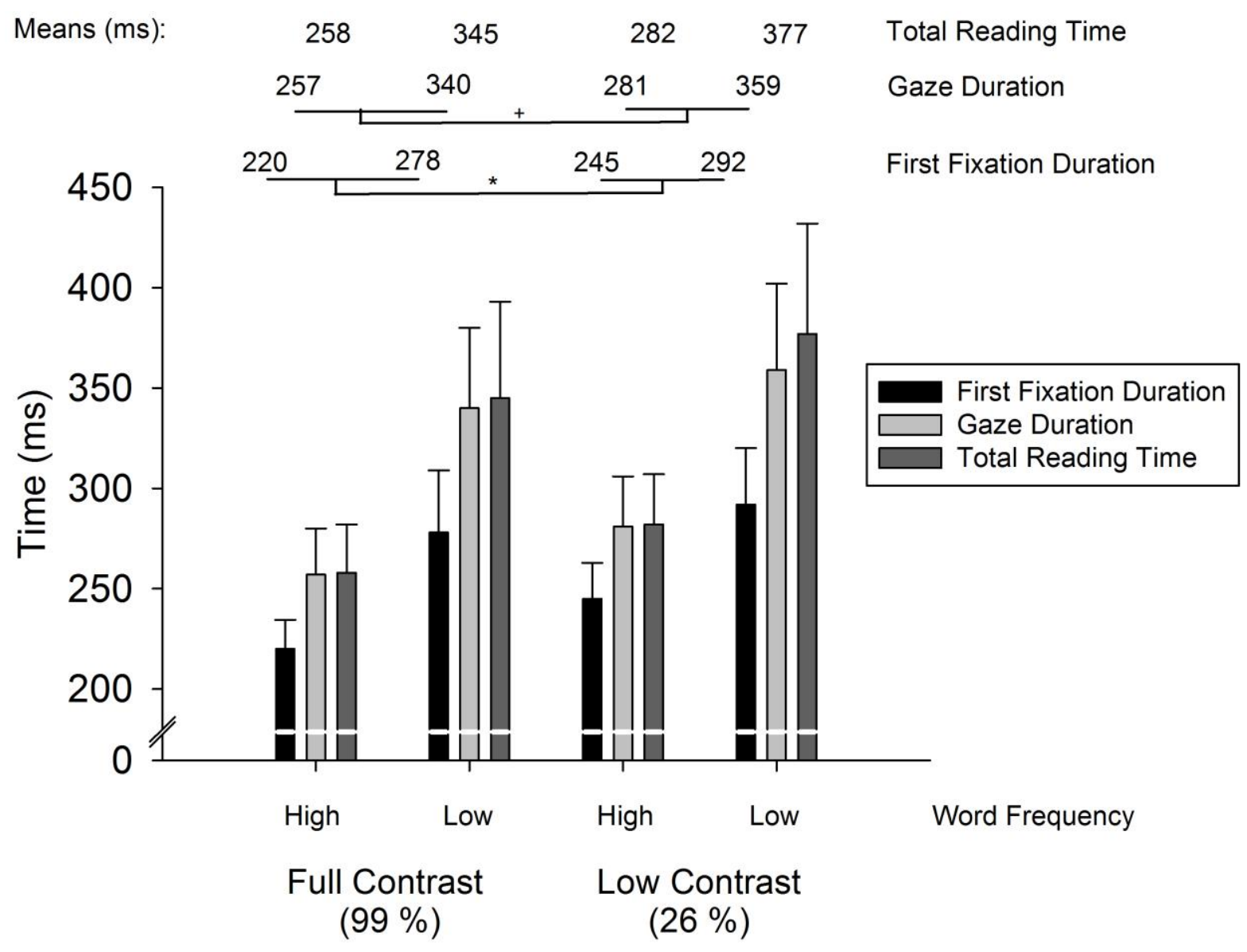


Figure 6 . Schematic representation of the number of activated neurons in the visual cortex in each presentation condition (from top, left to right: binocular reading with full contrast, binocular reading with reduced contrast; bottom, left to right: monocular reading with the left eye receiving the stimulus, monocular reading with the right eye receiving the stimulus. (based on reports by Avidan et al. (2002)).

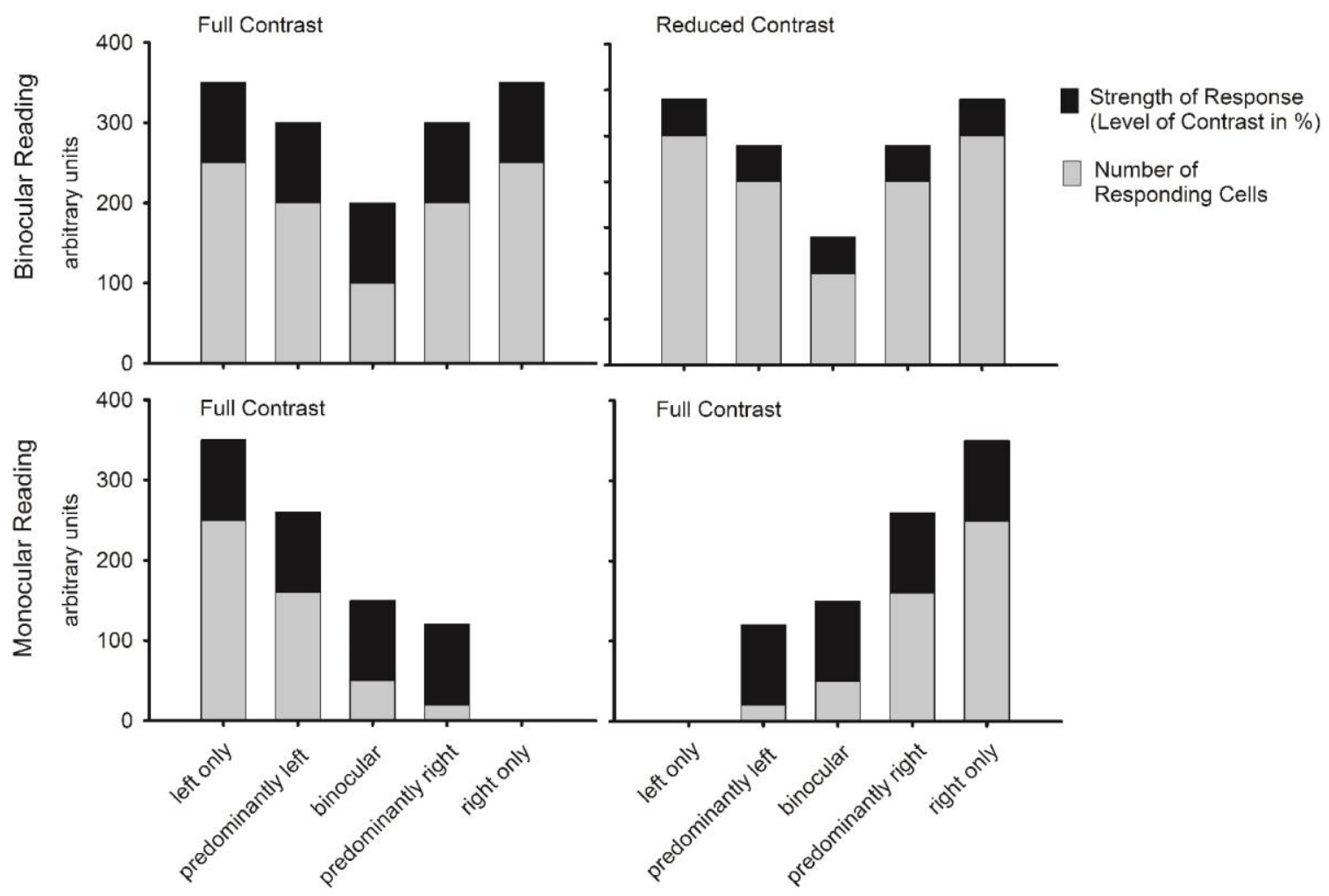

